\title{
The evolutionary ecology of the major histocompatibility complex
}

\author{
SB Piertney and MK Oliver \\ School of Biological Sciences, University of Aberdeen, Zoology Building, Tillydrone Avenue, Aberdeen AB24 2TZ, UK
}

The major histocompatibility complex (MHC) has become a paradigm for how selection can act to maintain adaptively important genetic diversity in natural populations. Here, we review the contribution of studies on the $\mathrm{MHC}$ in non-model species to our understanding of how selection affects $\mathrm{MHC}$ diversity, emphasising how ecological and ethological processes influence the tempo and mode of evolution at the $\mathrm{MHC}$, and conversely, how variability at the MHC affects individual fitness, population dynamics and viability. We focus on three main areas: the types of information that have been used to detect the action of selection on MHC genes; the relative contributions of parasite-mediated and sexual selection on the maintenance of MHC diversity; and possible future lines of research that may help resolve some of the unanswered issues associated with $\mathrm{MHC}$ evolution.

Heredity (2006) 96, 7-21. doi:10.1038/sj.hdy.6800724; published online 10 August 2005

Keywords: balancing selection; mate choice; MHC; parasites; sexual selection

\section{Introduction}

Determining the relative contributions of different stochastic and deterministic microevolutionary processes in the maintenance of genetic diversity in natural populations has been a major focus in evolutionary biology for several decades. The advent of allozyme electrophoresis in the 1960s (Harris, 1966; Lewontin and Hubby, 1966) prompted a proliferation of studies that examined genetic diversity across a broad taxonomic spectrum, and fuelled the neutralism vs selectionism debate that is still ongoing (Hey, 1999). Latterly, a burgeoning amount of DNA sequence information has facilitated efforts to identify the effects of selection on different gene regions and estimate the distribution of selective effects across the genome (Ford, 2002). Such data, however, does not necessarily help clarify what processes underpin selection, as DNA sequence information may not help to determine a gene's function.

Our understanding of how selection can act to maintain adaptive polymorphism in natural populations remains based on a small number of key gene regions, such as the major histocompatibility complex (MHC). The MHC has been characterised at the molecular level for a considerable number of years, and research describing MHC diversity has been extensive. Notwithstanding, the MHC remains a potent model on which competing hypotheses on the causes and consequences of selection can be tested.

The MHC is central to the vertebrate immune system. It is a multigene family that encodes key receptor

Correspondence: SB Piertney, School of Biological Sciences, University of Aberdeen, Zoology Building, Tillydrone Avenue, Aberdeen AB24 2TZ, UK. E-mail: s.piertney@abdn.ac.uk

Received 1 March 2005; accepted 27 June 2005; published online 10 August 2005 molecules that recognise and bind foreign peptides for presentation to specialist immune cells and subsequent initiation of an immune response (Klein, 1986). From an evolutionary perspective, the pre-eminent feature of the MHC is the extreme diversity that is observed at expressed loci. The MHC contains the most variable functional genes described in vertebrates. At three of the more variable human MHC loci, HLA-A, HLA-B and HLA-DRB1, 243, 499 and 321 alleles have been resolved worldwide, respectively, and nucleotide diversity in the human MHC is up to two orders of magnitude higher than the genomic average (Gaudieri et al, 2000; Garrigan and Hedrick, 2003). As more MHC genes are examined from an increasing number of species across a broad taxonomic range, it is apparent that such high diversity is a characteristic feature of MHC loci.

A pressure to maintain high allelic diversity at MHC loci might appear intuitively obvious, given that individuals or populations with higher sequence variation at MHC loci can identify and process a larger number of pathogenic antigens, and as such combat a wider range of immune insults. However, despite sustained effort we are still far from properly understanding what evolutionary, ecological and ethological processes generate, and more importantly maintain, MHC diversity in natural populations (Potts and Slev, 1995; Edwards and Hedrick, 1998).

The critical role in the immune recognition of parasites and pathogens means that the MHC might also be associated with a number of quantitative traits linked to the fitness and behaviour of individuals in natural populations. As such, the evolutionary dynamics of the MHC has become of relevance in ecology, population biology and conservation, and a paradigm for adaptively important genetic diversity. The potential ecological significance of the MHC was mooted while there was still a paucity of data on MHC variation from non-model 
species in natural populations, but it was predicted that despite the potentially intimidating pre-requisite barrier of characterising MHC homologues in non-model species, there would be a rapid proliferation of studies across a range of vertebrate species (Potts and Wakeland, 1990, 1993; Hedrick, 1994; Lenington, 1994; Edwards et al, 1995; Edwards and Hedrick, 1998). It was also suggested that widespread characterisation of MHC diversity in natural populations would add considerably to our understanding of the tempo and mode of MHC evolution by explicitly examining relationships with ecological processes that had been deemed to drive the evolutionary dynamics (Edwards et al, 1995).

This review is not directed at providing an exhaustive synthesis of the literature on levels, causes and consequences of MHC diversity. Instead, we highlight key studies on classical laboratory model species, and more recent studies from non-model species in natural populations that have added to our understanding of MHC evolution. Other reviews have followed a similar thread (Apanius et al, 1997; Bernatchez and Landry, 2003; Garrigan and Hedrick, 2003), but such is the degree of dynamism in this field that even in the few years since their publication, the number of studies on non-model species has increased dramatically, as has our overall understanding of the ecological significance of $\mathrm{MHC}$ diversity.

\section{The structure and function of the MHC}

The primary role of the MHC is to recognise foreign proteins, present them to specialist immune cells and initiate an immune response (Klein, 1986). In general, foreign proteins enter cells either by infection or by phagocytosis into antigen-presenting cells such as macrophages. These foreign proteins are broken down into small peptides and loaded onto specific MHC molecules. A subset of these protein/MHC complexes are then transported to the cell surface and presented for interrogation by the circulating T-cell population. A complex cascade of immune responses is triggered when the $\mathrm{T}$ cell binds to the presented peptide.

The MHC gene family encompasses two main subgroups of immunologically active molecules. Class I molecules are expressed on the surface of all nucleated cells except sperm cells and some neurons. They present endogenously derived peptides to $\mathrm{CD} 8+$ cytotoxic T-cells, so are primarily associated with defense against intracellular pathogens such as viruses. Class II molecules are present on antigen-presenting cells like macrophages, lymphocytes and dendritic cells, and present processed exogenous antigens to CD4 + T-helper cells. As such, class II molecules are associated with immune insults derived from extracellular parasites and pathogens.

The MHC molecule comprises an immunoglobulin 'stalk', which anchors the molecule to the cell surface, and a 'basket' receptor called the peptide-binding region (PBR; also called the peptide-binding groove, peptidebinding site, antigen recognition site or antigen presentation site). It is the PBR that is responsible for antigen recognition, and a match between $P B R$, antigenic peptide and T-cell receptor is required to produce an immune cascade. Although PBRs do show a degree of specificity, a single $\mathrm{MHC}$ molecule can bind multiple peptides that have common amino acids at particular anchor positions (Altuvia and Margalit, 2004).

Class I MHC molecules are heterodimers, comprising a transmembrane peptide (class I heavy chain), and three extracellular domains $(\alpha 1, \alpha 2, \alpha 3)$ each of which is encoded by a different exon from a single gene. The Class I PBR consists of two $\alpha$-helices next to a $\beta$-pleated sheet, formed by the $\alpha 1$ and $\alpha 2$ domains of the class I heavy chain (Jeffrey and Bangham, 2000). The MHC class II molecule is a heterodimer that consists of two transmembrane proteins, an $\alpha$ and a $\beta$ chain, which are encoded by two separate genes. Specific sites within both chains form the Class II PBR.

The genetic architecture of the MHC has been detailed for several model vertebrate species, most notably in humans (termed HLA; MHC Sequencing Consortium, 1999), mouse (H-2; Younger et al, 2000), rat (RT-1; Gunther and Walter, 2001; Hurt et al, 2004) and chicken (B-locus; Kaufman et al, 1999). There are similarities across these model systems in MHC structure, in that the class I and class II genes are linked together in a single gene complex in each case (Hughes and Yeager, 1998; Hess and Edwards, 2002). There are also, however, some striking differences. For example, the mammalian MHC encodes multiple loci for both class I and class II molecules, whereas in chicken the B-complex codes for two class I and two class II genes, and only one in each class is polymorphic and expressed at high levels (Guillemot et al, 1989; Kaufman and Salomonsen, 1997). An increasing number of MHC genes from non-model species are being characterised for comparison (Shiina et al, 2002; Kelley et al, 2005), and are highlighting considerably more variation in architecture. Large differences in the number of MHC loci are apparent across species, and some groups have silenced particular loci or have them arranged in unlinked gene clusters (Flajnik et al, 1993; Hansen et al, 1999; Kuroda et al, 2002). What is clear is that despite the conserved proximate function of $\mathrm{MHC}$ in immune recognition, the architecture of MHC genes varies sufficiently that a small number of model species is insufficient to describe the complex processes of antigen binding and recognition.

\section{MHC diversity}

Several lines of evidence from a large body of empirical data indicate that positive selection operates on MHC loci to maintain MHC variation. A number of different statistical tests can be used to test for selection on DNA sequences (reviewed in Kreitman and Akashi, 1995; Hughes, 1999; Kreitman, 2000; Ford, 2002; Garrigan and Hedrick, 2003). Here, we highlight those that have been frequently used in studies on MHC. These can be categorised as detecting selection in contemporary populations and the current generation, over the history of populations, and over the evolutionary history of species.

\section{Detecting selection in contemporary populations}

Selection acting in contemporary populations is expected to have a detectable effect on genotypic frequencies within that population (Hedrick et al, 2000). Overdominance models of selection predict that heterozygote genotypes will be fitter than homozygote genotypes 
(Doherty and Zinkernagel, 1975) given that two variant alleles will identify a broader range of pathogens. As such, if the intensity of selection is sufficient, there can be detectable deviations from Hardy-Weinberg proportions in adult populations, and/or deviations from Mendelian proportions in offspring, with an over-representation of heterozygote genotypes in both cases. Potts et al (1991) showed consistent deficiencies in the number of $\mathrm{MHC}$ homozygotes in the progeny of mice. However, other studies have detected little or no deviation from HardyWeinberg expectations (Paterson et al, 1998; GutierrezEspeleta et al, 2001; Seddon and Ellegren, 2004), perhaps suggesting that selection is spatially or temporally variable, that it cannot be detected in a single generation, or does not conform to a simple overdominance mechanism. It is also possible that studies lack sufficient sample size or allelic diversity at the MHC to have the statistical power to detect any effects, or that demographic processes acting on small or fluctuating populations mask any observable bias (Seddon and Ellegren, 2004)

\section{Detecting selection over the history of a population}

The effects of selection acting through the course of the history of a population can be detected from information on the frequency of alleles and the distribution of mutations within and between populations. Ewens (1972) highlighted that under neutral theory there is a low probability of an even frequency distribution for all alleles within a population. As such, there is an equilibrium distribution for heterozygosity for a given number of alleles and a known sample size when only mutation and drift are operating. Watterson (1978) proposed that deviation from such an equilibrium is an indicator of departures from neutrality and hence selection. The so-called Ewens-Watterson test of neutrality has been used to confirm the effects of balancing selection acting on the MHC in both non-model species (Paterson, 1998; Landry and Bernatchez, 2001; Miller et al, 2001; Hambuch and Lacey, 2002) and humans (Mack et al, 2000; Begovich et al, 2001).

A number of studies that have utilised the EwensWatterson test in multiple local populations have found variation in the level of decreased homozygosity among the different populations. In wild Atlantic salmon (Salmo salar), evidence for class II $\beta$ MHC diversity maintained by balancing selection was found in only six out of 14 populations (Landry and Bernatchez, 2001). Similarly, in sockeye salmon (Oncorhynchus nerka), a deficit of homozygosity at the MHC class II $D A B-\beta 1$ locus was observed in 13 of 31 populations (Miller et al, 2001). Such observations were attributed to variation in the strength and nature of selection across populations. However, the Ewens-Watterson test assumes that the populations examined are at equilibrium and have remained at constant size through evolutionary time (Nei, 1987). Given that the demographic history of the vast majority of natural populations involves fluctuations in size, it is unclear whether these patterns reflect a violation of the assumptions of the Ewens-Watterson test, or actual spatio-temporal variation in selection.

In an attempt to obviate this problem, patterns of $\mathrm{MHC}$ variation are frequently compared with those expected from neutral expectations, which are empirically derived from markers such as microsatellites or mitochondrial DNA sequences. Studies have generally taken one of two approaches. Firstly, by contrasting levels of MHC and neutral diversity within populations. Given that demographic processes are predicted to affect all loci, whereas selection will not influence the allele frequency distribution of neutral markers, the effects of variation in population size and other historical processes can be detected and controlled for. Secondly, by comparing levels of population divergence derived from both MHC and neutral markers. If selection is operating, and is relatively constant across populations, then it is expected that measures of population divergence should be lower for MHC alleles than neutral microsatellites as balancing selection will create a more even spatial distribution of alleles, or may favour new or rare alleles, and hence dispersers with novel genotypes enjoy a higher effective migration rate. Conversely, if selection varies, then MHC divergence is expected to be higher than estimated from neutral markers.

Several studies have used either or both of these approaches to examine the effects of selection acting on MHC diversity in populations. However, few studies have actually found an among-population effect consistent with balancing selection. Instead, studies have identified that either the strength of selection on MHC genes is weak relative to other microevolutionary forces acting in subdivided populations, or that selection pressures vary across populations, potentially as a result of heterogeneity in parasite load or diversity.

Westerdahl et al (2004) observed that the frequency of two (out of 23) specific MHC class I alleles varied more between cohorts of great reed warblers (Acrocephalus arundinaceus) than expected from random, whereas microsatellite markers showed fluctuations consistent with stochastic variation. This was used as evidence of the effects of selection rather than demographic factors in driving MHC variation.

Sommer (2003) found that genetic divergence estimates for both MHC DQA and DRB genes between two remnant populations of Malagasy giant jumping rat (Hypogeomys antimena) were much lower than those derived from mitochondrial control region DNA sequences. This could be explained by balancing selection producing a more even allele frequency distribution over the two subpopulations. However, this could also be influenced by sex-biased dispersal with a high level of female philopatry. Sequence analysis of the DRB PBR revealed a pattern consistent with the effects of selection at some time during evolutionary history, but such effects are probably now outweighed by contemporary population effects.

Similarly, Boyce et al (1997) compared patterns of diversity for MHC and microsatellite loci in 11 populations of bighorn sheep (Ovis canadensis). A high incidence of mortality attributed to infectious disease in these populations (Buechner, 1960) implies the potential for pathogen-mediated selection on MHC loci (Boyce et al, 1997). However, neither MHC nor microsatellite deviated significantly from the Hardy-Weinberg expectations and mean overall heterozygosity was higher for microsatellites than for MHC loci. It was concluded that if balancing selection was operating, then its effect is sufficiently weak to be masked by other microevolutionary forces. Similar conclusions were reached by 
Miller et al (2004) from bottlenecked populations of New Zealand robins Petroicidae, and Huang and Yu (2003) from 19 populations of the Southeast Asian house mouse Mus musculus castaneus in Taiwan.

Miller et al (2001) examined variation at the MHC class II $D A B-\beta 1$ locus for 31 populations of sockeye salmon Oncorhynchus nerka within the Fraser River drainage. They reported that $25 \%$ of variation at the $\beta 1$ locus was apportioned between populations compared to $5 \%$ at neutral markers. Similar patterns of increased MHC population differentiation relative to neutral loci have also been observed in Atlantic salmon (Salmo salar) (Landry and Bernatchez, 2001). Both of these studies emphasise the potential for opposing directional selection working at different geographic scales to increase between-population differences in MHC variation.

The major concern with studies that compare microsatellites and MHC markers in this way is that there is little consistent theory to derive predictions on the comparative patterns or between-population divergence for neutral loci and genes under selection in a subdivided population (Schierup, 1998; Schierup et al, 2000; Muirhead, 2001). Certainly, the effects of demographic history or social structure could confound any comparative test.

\section{Detecting selection over the evolutionary history of a species}

Selection is expected to both increase the apparent rate of nucleotide substitution relative to neutral expectations, and also retain mutations longer than would normally be expected under a neutral model. The detection of these sorts of effects is used by several approaches aimed at detecting positive selection in MHC genes.

The ratio of nonsynonymous (amino-acid altering) to synonymous (silent) nucleotide substitutions per nonsynonymous and synonymous site $(\mathrm{dN}: \mathrm{dS})$ can be used to test for balancing selection at any gene region (Hill and Hastie, 1987; Hughes and Nei, 1988). Synonymous mutations do not affect amino-acid composition and are therefore effectively neutral. As such, the rate of synonymous substitution should equal the mutation rate (Kimura, 1983). Nonsynonymous mutations, however, that do alter amino-acid composition, are more likely to be under selection. Deleterious nonsynonymous mutations are generally removed by purifying selection, making the rate of nonsynonymous evolution lower than the neutral rate, resulting in $\mathrm{dN}: \mathrm{d} S<1$. Conversely, beneficial nonsynonymous mutations will be retained by selection, increasing the rate of evolution relative to the neutral rate, resulting in $\mathrm{dN}$ : $\mathrm{dS}>1$. Therefore, if balancing selection favours diversity at the PBR of MHC genes, advantageous nonsynonymous mutations will be retained and a high ratio of nonsynonymous to synonymous substitutions will be observed. Tests of deviation of $\mathrm{dN}$ :dS from parity are becoming increasingly sophisticated (Nielsen, 1997; Yang and Nielsen, 2000; Bierne and Eyre-Walker, 2003), and can now explicitly examine which amino-acid sites show the most potent signatures of selection (Nielsen and Yang, 1998; Yang et al, 2000; Suzuki, 2004; Massingham and Goldman, 2005). Such approaches will prove useful in studies of the MHC, as the effects of selection on specific peptide-binding codons can be ascertained.
Application of $\mathrm{dN}: \mathrm{dS}$ tests across a range of vertebrate species confirms the actions of balancing selection at MHC regions (Hughes and Nei, 1988, 1989; Slade and McCallum, 1992). Indeed, Bernatchez and Landry (2003) reported a meta-analysis including 48 studies of which only one did not have an excess of nonsynonymous to synonymous substitutions. One disadvantage of using $\mathrm{dN}: \mathrm{dS}$ is that the accumulation of high ratios may occur over large timescales (10000-100000 generations), and if selection is relaxed, the time for the ratio to return to equivalence can be even longer (Garrigan and Hedrick, 2003). As such, elevated dN:dS can provide powerful evidence that balancing selection has operated on a gene extensively at some period in its evolutionary history, but provides little insight as to the timing or cause of selection. dN:dS may thus have limited applicable value when attempting to understand the nature of selection acting in contemporary populations.

A second approach used to detect the effects of selection acting through evolutionary history of a species is the occurrence of extensive trans-species allelism (also called trans-species polymorphism and originally transspecies evolution; Klein, 1980). This is the non-neutral retention of alleles among species such that gene trees fail to provide an accurate representation of the species relationships. Coalescent and neutral theories predict that immediately following divergence from their ancestral form, two species will share a proportion of alleles at any given locus. Over time, this proportion is reduced by stochastic and/or deterministic microevolutionary forces until each sister species has a distinct set of alleles. From a phylogenetic perspective, this process will see a gradual progression from polyphyly, through paraphyly, to reciprocal monophyly, and this end point should be reached in $<4 N$ generations for neutral alleles (where $N$ is the population size). Balancing selection can act to retain alleles among species for considerably longer periods of time (Takahata and Nei, 1990), increasing the time over which there is incomplete lineage sorting and delaying the time to monophyly. As a result, MHC gene phylogenies can pre-date the species phylogenies from which they were derived. Such trans-species allelism has been identified in a wide range of taxa including salmonids (Miller and Withler, 1997; Garrigan and Hedrick, 2001), ungulates (Van Den Bussche et al, 2002), pinnipeds (Hoelzel et al, 1999), rodents (Musolf et al, 2004), geckos (Radtkey et al, 1996) and warblers (Richardson and Westerdahl, 2003). However, transspecies polymorphism is apparently not ubiquitous for MHC genes. Pfau et al (2001) found concordance between species and gene trees for an MHC DQA locus when comparing alleles from the cotton rat (Sigmondon hisipidus) with other rodents. Moreover, mutational processes such as gene conversion and interlocus recombination can bias analysis by affecting divergence and retention times (Martinsohn et al, 1999). As such, some MHC alleles may be considerably younger than they would appear from an MHC-based phylogeny. Some studies have managed to provide a functional validation that alleles have been retained over evolutionary time scales. Phylogenetic analysis indicated that related MHC-DRB alleles are present in humans, chimpanzee and other primates (Geluk et al, 1993). The binding and antigen presentation capacity of these transspecific alleles for a mycobacterial antigen was similar 
and the homologous MHC proteins were also competent for presentation to a human T-cell line. This emphasises that the MHC allele members must have been present in a common ancestor of these primate species that lived about 30 million years ago, and that function has been conserved across speciation events.

\section{What underpins selection at the MHC?}

Garrigan and Hedrick (2003) highlighted that some signals of selection may be detectable after only a short period of selective pressure, but that this signal can remain for considerable periods of time, certainly well after selection has been relaxed. As such, little information on the timing of selection is achieved. Perhaps more importantly though is that this can prevent inference about those processes that might underpin selection. This has been a major issue in studies on MHC evolution (Apanius et al, 1997). It has been proposed that the mechanisms are associated with either parasite-mediated or sexual selection, although these two paradigms are not necessarily mutually exclusive. Evidence in favour of both of these forces is outlined below. One strength of examining non-model systems in natural populations is that it allows examination of selection acting in an ecological context over short time scales which enhances the potential for identifying sources of selective pressure.

\section{Parasite-mediated selection and MHC evolution}

The fundamental role of the $\mathrm{MHC}$ in combating immune insults from parasites and pathogens underpins the concept that MHC polymorphism is maintained through some form of pathogen-driven selection (Doherty and Zinkernagel, 1975; Hedrick and Kim, 1998). Initially, it was considered that this might not be the case, given that the human MHC is intimately linked with autoimmune disease, such as insulin-dependent diabetes and multiple sclerosis, rather than with infectious pathogens (Kaufman et al, 1995). However, relationships between certain human diseases, such as malaria, and specific HLA class I and class II DRB haplotypes are now well established (Hill et al, 1991, 1992, 1994; Hill, 1998, 1999). Similarly, in chickens, an extremely strong association exists between the class II B21 allele with resistance, and the class II B19 allele with susceptibility, to Marek's disease, a potentially lethal $\mathrm{T}$ lymphoma induced by a herpes virus (Briles et al, 1977). Experimental studies in mice have demonstrated the influence of MHC genes in both resistance and susceptibility to a variety of disease ranging from gastrointestinal helminths to viruses (for a comprehensive overview, see Apanius et al (1997)).

Once a link between MHC type and disease resistance was established, emphasis shifted to understanding the mechanistic processes most likely to explain the high observed MHC diversity. Two primary theories were proposed - the negative frequency-dependent selection hypothesis and the overdominance hypothesis (Takahata and Nei, 1990; Slade and McCallum, 1992).

The negative frequency-dependent selection (or rare allele advantage) hypothesis proposes that new or rare alleles may incur a selective advantage when a novel pathogen strain arises. If the rare allele confers an advantage over a common allele, then it would subsequently increase in frequency. As the advantageous allele becomes more common, selection will favour novel pathogenic strains that are not recognised by this allele. If the pathogen is unrecognised, it will increase in frequency and selection will favour a different MHC allele that can recognise and process that pathogen (Slade and McCallum, 1992). Mechanistic models have shown that negative frequency-dependent selection can retain a large number of MHC alleles in flux (Borghans et al, 2004). Apanius et al (1997) estimated that it would take almost 1000 host generations for a deleterious MHC allele that does not recognise the dominant pathogen to deplete in frequency from 1 to $0.1 \%$. Empirically, frequency-dependent selection is hard to detect, given the temporal aspects implicit in the relationship among alleles. Inference can be made from the spatial variation in the relationship between resistance and $\mathrm{MHC}$ type (Hedrick et al, 1976; Gillespie, 1978; Hill et al, 1994), or from changes in MHC allele frequency over short time scales (Westerdahl et al, 2004). This, however, can be problematic as it provides little scope for differentiating between frequency-dependent selection and directional selection for an individual allele that may go to fixation.

The overdominance hypothesis was first suggested by Doherty and Zinkernagel (1975), who proposed that immune competence, in terms of the recognition and elimination of pathogens, could be substantially enhanced by heterozygosity at MHC loci, as heterozygotes recognise a wider variety of antigens derived from multiple pathogens and so have a higher relative fitness than either homozygote. This supposition depends somewhat on the degree of divergence in the structure of peptide groups bound by different alleles, and as such, individuals with haplotypes showing less overlap in binding specificity would be favoured. From an empirical perspective, the overdominance hypothesis predicts a stable polymorphism, and can only be tested fully in systems with multiple pathogen strains. Some models, however, have demonstrated that overdominance can only retain high levels of MHC diversity in natural populations if all heterozygote genotypes have equivalent fitness (De Boer et al, 2004), which is arguably unrealistic.

It should be emphasised that there are several potentially confounding problems trying to separate the effects of dominant vs overdominant processes as the primary driver of selection, and these problems may be exacerbated in natural populations that examine relatively small sample sizes and where populations are exposed to a generally unknown range of parasite and pathogen insults. Firstly, Apanius et al (1997) highlighted an implicit frequency-dependent component to the heterozygote advantage hypothesis in that rare alleles occur disproportionately in heterozygous genotypes, whereas common alleles occur disproportionately in homozygous genotypes. In this case, rare alleles would always seem to have an advantage, but the relative contributions of overdominance or frequencydependent selection cannot be separated. Secondly, in the strictest sense, overdominance can only be inferred when the fitness of the heterozygote genotype is significantly greater than both homozygotes. Frequently, the fitness of the heterozygote is greater than the average of the two homozygotes, but not significantly greater 
than the fittest homozygote, as fitness is a consequence of the presence of a dominant resistant allele that both the heterozygote and homozygote genotypes carry. In this case, there is a heterozygote advantage in the broadest sense, but this is not synonymous with overdominance. The two processes are predicted to be considerably different in their efficacy for retaining diversity in natural populations (Penn et al, 2002; McClelland et al, 2003).

Experimental studies have been used to explicitly test the overdominance hypothesis, by infecting laboratory populations with multiple pathogens. Penn et al (2002) showed that MHC heterozygote mice had greater survival and clearance capacity to avirulent Salmonella infections than homozygote mice. However, the heterozygote genotypes were not significantly more resistant than the most resistant homozygote, inferring that resistance was dominant rather than overdominant. McClelland et al (2003) have shown a true overdominant effect in mice coinfected with Salmonella and Theiler's murine encephalomyelitis virus. When the two heterozygote haplotypes had opposite susceptibility profiles to the two pathogens (ie haplotype 1 is resistant to one and susceptibility to the other, and vice versa for haplotype 2 ), heterozygote genotypes were fitter than both homozygotes.

Studies on non-model species from natural populations have added to our understanding of the significance of disease association in MHC evolution, both by clarifying the intimate relationship between MHC type and resistance to specific parasites and pathogens, and also determining the relative contributions of dominant vs overdominant selection in maintaining MHC diversity.

A large number of studies have highlighted significant relationships between MHC type and parasite burden. These studies vary in their degree of complexity and sophistication, ranging from moderately simple indirect correlative studies, to large-scale, replicated experimental manipulations.

In subterranean mole rats Spalax ehrenbergi, MHC heterozygosity was highest in the most humid/warm areas where infectivity of gamasid mites and endoparasitic helminths was also highest (Nevo and Beiles, 1992). This suggested that selective pressures arising from macroparasite burdens help to maintain differential levels of MHC diversity across geographical areas with varying environmental characteristics.

In Scottish Blackface sheep, Schwaiger et al (1995) and Buitkamp et al (1996) detected a significant influence of MHC genes in regulating faecal egg burdens of the gastrointestinal helminth Ostertagia circumcincta, with 58fold, eight-fold and 218-fold reductions in faecal egg counts in 6-month old lambs carrying particular alleles at DRB-1, class I and class II $\beta$ (DY) genes, respectively, relative to lambs carrying the most common allele in each case.

Paterson et al (1998) showed that specific MHC alleles affected both resistance and susceptibility to gastrointestinal nematodes in a natural population of Soay sheep (Ovis aries), as did Meyer-Lucht and Sommer (2005) in yellow-necked mouse (Apodemus flavicollis) and Schad et al (2005) in Malagasy mouse lemurs (Microcebus murinus). In striped mice (Rhabdomys pumilio), MHC DRB heterozygosity influenced infection status to parasites, and particular alleles occurred more frequently than expected in both high and low parasitised individuals
(Froeschke and Sommer, 2005). This study provides evidence that both overdominant and frequency-dependent selection may operate simultaneously.

A corollary of heterozygote advantage models that indicate that individuals with two alleles have increased fitness relative to those with one, is that across multiple paralogous genes, an increasing number of alleles should confer a greater ability to respond to a broad range of pathogens and hence maximise immunocompetence to multiple simultaneous infections. This hypothesis was tested in three-spined sticklebacks (Wegner et al, 2003a, b) exposed to a range of parasite species across lake and river populations. Between 13 and 28 class II $\beta$ MHC alleles were resolved within populations, and between two and nine alleles across duplicated genes within individuals. The lowest parasite burdens, however, were found in those individuals with an intermediate number of alleles (ca. 5). It was proposed that high intraindividual diversity might reduce fitness by overdepletion of the T-cell repertoire during self-tolerance induction in the thymus. This in turn would reduce the potential that an immune response could be mounted against any given foreign antigen (Nowak et al, 1992). However, selection for intermediate numbers of alleles was not observed in hairy-footed gerbils (Gerbillus paeba; Harf and Sommer, 2005). Individuals with an intermediate number of alleles across duplicated loci were more intensively infected with intestinal helminth parasites than individuals with more or fewer alleles. Moreover, Hedrick (2004a) examined whether selection for intermediate numbers of alleles could retain high levels of diversity over time in natural populations, and concluded this was only possible with unrealistically high rates of mutation. Wegner et al (2004) responded by highlighting that processes other than mutation, such as recombination, may be operating.

One potential problem with attempting to link any aspect of the MHC to parasite resistance in natural populations is that studies typically resolve high numbers of MHC alleles at low frequencies, which combined with relatively low sample sizes, makes it difficult to harness adequate statistical power (Hill, 1998). Although the selection advantage of MHC heterozygosity may be considerable over evolutionary timescales, it is relatively weak and hard to detect in contemporary populations, especially those of the size typically sampled in most studies. Apanius et al (1997) highlighted that to demonstrate a 0.05 difference in fitness between heterozygotes and homozygotes would require a sample size of over 6000. If multiple pathogens define the selection pressure, then the cumulative value of 0.05 would have to be divided per pathogen. Moreover, if different selection mechanisms such as resistance to infectious, autoimmune and malignant disease vary in the way in which they act upon MHC polymorphism, then selection operating through one mechanism may be obscured by other mechanisms acting in other ways (Apanius et al, 1997).

While such issues might foster a perception that studies on natural populations that attempt to correlate parasite load or disease resistance to particular MHC alleles or heterozygosity are fatally compromised by power, two alternative approaches have been utilised: the use of experimental challenges, and examination of MHC against lifetime reproductive success. 
Challenge experiments on individuals taken from natural populations offer a powerful alternative approach to correlative association for examining the efficacy of particular MHC haplotypes against disease or parasites. They are better suited for replication and large sample size, and hence abrogate many of the problems associated with obtaining sufficient statistical power to detect associations.

Langefors et al (2001) found an association between certain MHC class II $\beta$ alleles and resistance to the bacterial pathogen Aeromonas salmonicida in experimentally challenged Atlantic salmon (Salmo salar). Lohm et al (2002) subsequently selectively mated the uninfected siblings of these fish, combining high- and low-resistance alleles within full-sibling families, thereby controlling for the potentially confounding effects of family. This study revealed a codominant pattern of resistance/susceptibility to $A$. salmonicida infection. Neither study found any evidence to support MHC heterozygote advantage, and in the former case it was suggested that the results were more consistent with the frequency-dependent hypothesis (Langefors et al, 2001).

Further experimental challenges of Atlantic salmon with infectious salmon anaemia virus as well as $A$. salmonicida employed very large sample sizes and found highly significant associations between independently segregated MHC loci and disease resistance (Grimholt et al, 2003). MHC heterozygosity (Arkush et al, 2002) and specific MHC alleles (Miller et al, 2004) have also been associated with resistance to infectious hematopoietic necrosis virus (IHNV) in Chinook salmon (Oncorhynchus tshawytscha) and Atlantic salmon (S. salar), respectively.

Experimental infection in other fish species compliments the work carried out on salmon. In Gila topminnows (Poeciliopsis o. occidentalis), MHC heterozygotes enjoyed a $15.5 \%$ higher survival relative to homozygotes following infection with an exotic fluke (Hedrick et al, 2001). Wedekind et al (2004) showed that certain MHC class II genotypes increased embryo survival in whitefish (Coregonus sp.) after infection by the bacterium Pseudomonas fluorescens.

While Apanius et al (1997) underlined potential power issues associated with correlative studies examining MHC type and parasite load, it was also highlighted that measuring alternative variables such as productivity and reproductive success might be considerably more powerful. Each small MHC-dependent effect may contribute additively to a more detectable relationship across a variety of fitness influencing parameters over an individual's lifetime. This approach was applied in a study of free-ranging rhesus macaques (Sauermann et al, 2001; Widdig et al, 2004), and provides strong indirect evidence for overdominant selection promoting $\mathrm{MHC}$ diversity in primates. Among male macaques, MHC class II heterozygotes sired significantly more offspring than homozygotes. No evidence of disassortative mating preference was found in the study population and the authors suggest increased resistance to parasites and reduced debilitative effects of injury-related infection as the most plausible explanation of increased reproductive success in MHC heterozygous males. Parasites such as helminths, although unlikely to lead to mortality, may cause lethargy, thereby reducing the ability of a male to gain access to a female and reducing reproductive success over time (Sauermann et al, 2001). Anti-helminth treatment improved the reproductive success of males, supporting suggested links between parasite burden and reproductive fitness.

\section{MHC-dependent sexual selection, mate choice and the MHC}

The second major paradigm for how MHC diversity can be maintained at high levels in natural populations invokes MHC-dependent sexual selection (Brown and Eklund, 1994; Jordan and Bruford, 1998; Penn and Potts, 1999). A number of adaptive hypotheses, which are not necessarily mutually exclusive, have been proposed to explain how MHC could influence mating behaviour and reproductive success. Those that have received most attention are: (1) MHC-related selective fertilisation (Wedekind et al, 1996; Rulicke et al, 1998; Wedekind et al, 2004); (2) MHC-dependent selective abortion (Alberts and Ober, 1993); (3) disassortative matings based on MHC genotype (Penn and Potts, 1999). Here, we focus on the latter, as this has been the primary focus for studies in non-model vertebrates. Furthermore, processes such as maternal-foetal interaction cannot be a mechanism that accounts for high MHC diversity in oviparous taxa.

From an individual's perspective, MHC-based mate choice would facilitate inbreeding avoidance between close relatives, enriching genome-wide variation in offspring. Also, since MHC heterozygotes can potentially combat a wider range of immune insults than homozygotes, individuals producing heterozygote offspring enhance progeny fitness by maximising immunological capability. These processes will maintain high levels of polymorphism and generate the heterozygote excesses and linkage disequilibrium characteristic of the MHC in natural populations (Klein, 1986; Hedrick, 1992; Apanius et al, 1997).

The concept that MHC genes could be intimately linked with sexual behaviour and mate choice has been intuitively attractive given that the primary function of the MHC is to distinguish self from non-self at the cellular level, and so could also underpin a mechanism that distinguishes relatives from non-relatives at an organismal level. Moreover, the complex architecture and high polymorphism inherent in the MHC provides the variability necessary for a genetically based recognition system (Grafen, 1990).

However, studies that have rigorously examined the role of $\mathrm{MHC}$ in mate choice have drawn mixed conclusions, and empirical data from non-model species in natural populations are few. Studies have generally taken one of two approaches: Firstly, determined whether there is direct evidence of MHC-based sexual selection from the types and frequency of $\mathrm{MHC}$ genotypes observed at the population level, family level or between mates. Secondly, examined whether there are any phenotypic correlates that allow an individual to assess the genotypic status of the MHC in another individual.

The most work on MHC-based mate choice has been undertaken on the mouse, and indeed it was the serendipitous observation of MHC-biased mate preference in crosses established to produce MHC-congenic mouse strains that initially suggested MHC-based sexual 
selection could occur (Yamazaki et al, 1976). Jordan and Bruford (1998) and Acaro and Eklund (1999) provide thorough summaries of the important studies on mating preferences among inbred, congenic and seminatural populations of mice. Initial experiments by Yamazaki et al (1976) showed that in four of six congenic mouse strains, males preferred to mate with MHC-dissimilar females. Subsequently, female mice were also shown to prefer MHC-dissimilar mates, and oestrus females preferred MHC-dissimilar odours (Egid and Brown, 1989). This overall picture of MHC-dissimilar preference is somewhat confused however because different genetic backgrounds influence the strength and direction of mate preference, with homozygotes displaying the strongest responses (Yamazaki et al, 1976).

Potts et al (1991) showed similar patterns for wild mice held in seminatural conditions. Consistent deficiencies in the number of MHC homozygotes (27\% across populations) were found in progeny relative to that expected under random mating. After controlling for other processes that could generate heterozygote excess, the authors concluded that MHC based mating patterns were responsible.

Following the initial work on mice, considerable effort was invested in examining MHC-based mate choice in humans. Mixed results were obtained. Hedrick and Black (1997) found no evidence for HLA-dissimilar mate choice in 11 south Amerindian tribes, whereas Ober et al (1997) did find evidence for negative assortative mating according to HLA type among 411 Hutterite couples, an isolated caucasian group in north America derived from 400 founders in the 19 th century.

Several studies have implicated olfaction as a mechanism by which an individual can assess the MHC type of another congener (Brown and Eklund, 1994). Although the process is not fully understood, MHC genes can affect the concentration of volatile acids that produce odour in sweat or urine (Yamazaki et al, 1979; Singh et al, 1987; Wedekind et al, 1995; Wedekind and Furi, 1997; Hurst et al, 2001; Beauchamp and Yamazaki, 2003; Santos et al, 2004). This could be used as a direct cue to avoid inbreeding, choose particular MHC genotypes or may provide an indication of infection status. Female mice have been found to be less attracted to a male's urine during infection with influenza, than before or after infection (Penn and Potts, 1998). It is also apparent that an individual's own mate choice decisions will be based on those that are experienced during early life, inferring some form of familial imprinting. Yamazaki et al (1988) showed through cross fostering experiments that an individual will choose MHC-similar mates if crossfostered to MHC-dissimilar parents. This issue was confused somewhat by subsequent studies that produced conflicting results (Acaro and Eklund, 1999).

Studies on MHC-based mate choice in humans and mice have courted both considerable controversy and criticism. The validity of experimental studies on mice has been questioned given that the use of inbred lines may selectively affect the very behaviours, especially female mate choice, that the experiments are attempting to examine (Manning et al, 1992). Also, MHC-congenic lines will differ across a large swathe of $\mathrm{MHC}$ region, not just the specific class I or class II loci that are supposedly the focus of selection. As such, MHC-based mate choice cannot be unambiguously separated from MHC-asso- ciated mate choice (Hughes and Hughes, 1995). A lack of repeatability of several studies, and an apparent plasticity in response across experiments, further questioned the robustness of the data, and the general relevance of mate choice as a primary driver of MHC diversity (Jordan and Bruford, 1998).

Irrespective of such criticism, an increasing number of studies are examining MHC-based mating preference in non-model systems. In wild ring-necked pheasants, Phasianus colchicus, male spur length is positively correlated with age, body size and viability. Females prefer to mate with males with longer spurs, and by doing so they improve chick survival rate (von Schantz et al, 1989). It was subsequently shown that male MHC haplotypes for both class I and class II $\beta$ correlate with spur length and male viability, indicating that females discriminate among males based on secondary sexual characters in order to pass on 'good genes' for disease resistance and improve fitness of offspring (von Schantz et al, 1996, 1997).

Similar inference was made by Ditchkoff et al (2001) for white tailed deer (Odocoileus virginianus). Associations were detected between certain MHC DRB genotypes, rates of antler development and body size, and also a negative relationship between antler size and abundance of abomasal helminths. As such, antlers represent an honest advertisement of parasite resistance, and a way females can choose males that provide offspring with superior disease resistance.

Olsen et al (1998) performed a series of fluvariumbased experiments to examine whether juvenile arctic charr (Salvelinus alpinus) could discriminate between individuals of different class II $\beta$ MHC genotypes. Individuals preferred water scented by an MHC-identical sibling over that scented by an MHC-different sibling over that scented by an MHC-different nonsibling. No preference was observed over a nonsibling that shared an MHC allele to a sibling that shared no MHC alleles, suggesting that some form of self-matching comparison of MHC may occur. A follow-up study (Olsen et al, 2002) showed that siblings isolated at fertilisation failed to show any kin-biased preferences for MHC genotype, which, as with other model species, implicates some form of familial imprinting requirement for effective MHC-based discrimination.

While the studies of Olsen and co-workers on charr highlighted a degree of kin discrimination, their data cannot be interpreted to conclude that individuals choose MHC-dissimilar mates to maximize the fitness of offspring. Landry et al (2001) have subsequently shown this does occur in natural populations of Atlantic salmon (Salmo salar). They highlighted that individuals prefer to mate with fish with functionally different MHC alleles to enhance MHC heterozygosity in offspring. Mating to minimize inbreeding was discounted given that the genetic relatedness of mates estimated from five microsatellite loci did not differ from expectations based on random mating

Several other studies not detailed here have also demonstrated MHC-dissimilar mating behaviour, including in Savannah sparrows Passerculus sandwichensis (Freeman-Gallant et al, 2003) and female sand lizards Lacerta agilis (Olsson et al, 2003, 2004).

Despite some persuasive evidence of the role of MHC in mate choice, several studies have also found no effect. 
Moreover, the number of studies highlighting no relationship between $\mathrm{MHC}$ and mate choice is likely to be conservative given the bias caused by an underreporting of negative results. Paterson and Pemberton (1997) found no evidence for MHC-dependent mate choice in Soay sheep (Ovis aries) and suggested that the strength of male-male competition is more important for determining mating success than intersexual mate choice. Similarly mate choice was determined to be independent of MHC type in female great reed warblers (Acrocephalus arundinaceus) (Westerdahl, 2004), rhesus macaques (Macaca mulatta) (Sauermann et al, 2001) and great snipes (Gallinago media) (Ekblom et al, 2004).

The gradual increase in studies examining MHCrelated mate choice has emphasised that choice can be based on different criteria, be that for specific alleles, genotypic dissimilarity or overall diversity (Tregenza and Wedell, 2000; Mays and Hill, 2004). Early studies such as that of von Schantz et al (1997) and von Schantz et al (1996) emphasised that specific MHC alleles can be advertised by extravagant secondary sexual characters. However, overall immunocompetence might not be based on the presence or absence of specific haplotypes, but by the combination of paternal and maternal genes. Indeed in bluethroats (Luscinia svecica), extra pair halfsibs have greater immunocompetence relative to their maternal and paternal half sibs, suggesting that particular combinations of alleles improve quality of offspring (Johnsen et al, 2000). As such, individuals must not only assess their potential mates quality but also how well they complement their own genes.

If individuals choose mates to maximise the immunocompetence of offspring, and resistance to parasites and pathogens is underpinned by several MHC loci, then individuals should choose based on the number of alleles across multiple loci, or the compatibility of these alleles to their own alleles at homologous loci. The potential for such 'allele counting' has been shown in wild threespined sticklebacks (Gasterosteus aculeatus). Reusch et al (2001) characterised MHC class II $\beta$ diversity at an estimated six loci simultaneously. It was shown that females prefer males that displayed 'many' alleles (6-8) rather than 'few' alleles (3-6). Females did not prefer MHC-dissimilar males, suggesting that allele counting is a more important process than disassortative mating. Given it has also been shown that individuals with an intermediate number of alleles had the lowest parasite burdens (Wegner et al, 2003a, b), mate choice in this case appears to be directed towards maximising immunocompetence across several paralogous loci.

\section{Summary and future directions}

The earliest reviews of MHC evolution were inevitably focused on studies from a small number of laboratory model species. It was suggested that expanding studies to include non-model species in natural populations would clarify the ubiquity of high diversity at MHC genes, the ecological and ethological processes responsible for underpinning selection, and the significance of MHC diversity in individual fitness and the viability of natural population (Edwards et al, 1995). The only perceived problem was that the requirement to clone and characterise MHC genes in non-model species might represent an impediment to studies in natural populations (Edwards and Hedrick, 1998).

This concern was clearly misplaced. The development of conserved PCR primers that amplify across diverse vertebrate taxa (eg Edwards et al, 1995) and an increasing amount of sequencing information from which to design degenerate PCR primers for specific taxonomic groups means that it is now relatively straightforward to target MHC loci (Potts, 1996; Edwards et al, 2000). Moreover, the development of rapid, high throughput screening techniques such as single-stranded conformational polymorphism (SSCP) and denaturing gradient gel electrophoresis (DGGE) means large numbers of individuals can be screened for MHC variation both rapidly and economically (Potts, 1996). As a consequence, a relatively large, and growing, body of empirical data now exists in non-model species examining levels of diversity at both class I and class II MHC genes, the evolutionary relationships among $\mathrm{MHC}$ alleles, and causative links between MHC diversity and parasite load, mate choice, individual fitness and lifetime reproductive success. Indeed, levels of MHC diversity in populations are increasingly being used in a conservation context to identify those populations that are relatively depaurperate in diversity. MHC variation is viewed as being a better marker for conservation not because it is a better proxy than any neutral marker for determining genome wide diversity, but because it is intimately associated with factors likely to impinge on individual fitness, population viability and evolutionary potential in a changing environment (Edwards and Potts, 1996; Hedrick, 1999; Arkush et al, 2002; Aguilar et al, 2004; Hedrick, 2004b; Seddon and Ellegren, 2004).

A major finding of work on non-model vertebrates is that it has, with rare exception, confirmed that MHC variation is strongly influenced by selection. The majority of studies, however, have identified that selection has operated at some point through evolutionary time rather than necessarily acting in the extant generation. It is also clear that data from non-model species is inconsistent with traditional models that explain high MHC diversity as a consequence of overdominant balancing selection with equivalence between different heterozygotes. Indeed, consistent associations between particular alleles and resistance to parasites, and variation in the difference in estimates of genetic divergence measured from MHC and neutral markers, would indicate that fitness is based on dominant, and not overdominant, associations. Even those studies that have inferred overdominance may in fact have detected heterozygote advantage through the effect of a dominant resistant allele rather than heterozygote superiority caused by true overdominance.

This large body of data obtained from non-model species in natural populations also has not identified which process(es) underpin selection at MHC genes. Evidence has accrued both in favour of the effects of parasites and mate choice in maintaining MHC diversity. Moreover, data can be selectively used to infer that individuals are choosing mates to maximise $\mathrm{MHC}$ heterozygosity, to minimise inbreeding, or selecting for a optimal number of alleles across several loci.

So where might future studies focus to clarify how $\mathrm{MHC}$ diversity is retained in natural populations, and its significance as ecologically meaningful genetic diversity 
likely to define individual fitness and population viability?

It is our view that first-and-foremost, studies must more rigorously characterise the diversity that is being detected. The ease with which $\mathrm{MHC}$ variation can now be resolved could paradoxically impede progress with our understanding of MHC dynamics. A large number of studies are characterising MHC variation from genomic DNA extracts with little or incomplete knowledge of (1) the number of loci that are actually being simultaneously PCR amplified; (2) whether any or all of these genes are actually expressed and (3) whether the variation that is resolved reflects sequence differences at structurally important regions such as the peptide-binding amino acids. Ultimately, an inability to determine the actual number of expressed loci, identify alleles as being structural MHC variants, assign alleles to loci and determine whether an individual is heterozygous or homozygous for a particular locus compromises rigorous statistical testing of association between MHC and parasite load or mating behaviour, either by introducing variation that is not directly under selection, or precluding detection of overdominant selection. It will be problematic, bordering on impossible, to be able to completely validate studies from mRNA extracts, especially from natural populations, and certainly if the species is of conservation concern (though see Miller and Lambert, 2003). However, every effort should be made to initially ensure that PCR primers do actually amplify single expressed products to clarify that subsequent analysis based on genomic DNA is appropriate (Piertney, 2003).

A further concern is that an increasing trend towards using noninvasive or nondestructive samples for characterising genetic diversity may introduce more genotyping errors, as proficient characterisation of $\mathrm{MHC}$ alleles from minute amounts of potentially damaged DNA will be problematic (see Knapp, 2005 and reply from Lukas and Vigilant, 2005).

One area where there will be continued emphasis in studies of natural populations is in the comparison of how neutral and MHC diversity is apportioned within and among populations to measure the effects of selection and infer how it varies across populations (Landry and Bernatchez, 2001; Miller et al, 2001; Sommer, 2003). However, there is a need to develop a more rigorous conceptual and theoretical framework that predicts how selection and drift will interact in naturally fragmented populations (Muirhead, 2001). Such models need to incorporate not only variation in population size and levels of dispersal but also variation in social structure within populations. In the broader field of population genetics, there is increasing emphasis on determining the extent of social affiliation within populations (Dobson et al, 1997, 1998; Girman et al, 1997; Dobson, 1998; Piertney et al, 1999) and on developing a framework to model neutral gene dynamics in socially structured populations (Chesser, 1991a,b; Sugg and Chesser, 1994; Sugg et al, 1996). Understanding how social structure affects MHC dynamics may be especially important given that social structure will influence the transmission of parasites and disease at a local scale, and also the potential for mate choice decisions will vary in response to levels of local inbreeding. Such processes do appear to be pertinent -
Hambuch and Lacey (2002) compared the strength of balancing selection between a social and a solitary species of tuco-tuco (Ctenomys sociabilis and C. haigi, respectively), testing the hypothesis that sociality affects parasite transmission that will influence selection. Selection coefficients were more than 50 times greater in the social species.

Studies that have compared genetic divergence from neutral and MHC markers infer spatial heterogeneity in parasite load as the main process explaining the observed patterns. However, such inference is often made without direct examination of how parasite load or diversity changes spatially, and hence patterns may simply reflect variation in demographic processes. Characterising variation in parasite intensity and diversity across populations is daunting, but will shed considerable light on our understanding of what maintains MHC diversity. Better still would be analysis of spatio-temporal variation in parasite pressure, and neutral and MHC variation. This allows more rigorous testing of frequency-dependent, antagonistic coevolution between parasites and host, but is logistically considerably more difficult. The ability to extract DNA from archived material facilitates the examination of temporal MHC dynamics, but ultimately studies may need to be designed that incorporate a temporal component.

In the context of understanding how mate choice affects MHC dynamics, it is still unclear whether individuals aim to reduce inbreeding, select for specific MHC alleles, ensure offspring are heterozygous at an MHC locus or maximise MHC diversity across several loci. It is probable that different species employ different strategies, and these may be context dependent, or vary over time. Certainly, mate choice for compatibility differs from other forms of sexual selection, such as good genes, as individuals will differ in their choice of mates, changing the evolutionary dynamics of sexual selection (Tregenza and Wedell, 2000). One obvious paradox that needs to be examined explicitly is whether there is a fitness benefit to increased genetic diversity and a tendency for females to use genetical dissimilarity as a criterion for mate choice, how can they use an absolute criterion such as ornamentation to assess a relative criterion such as compatibility?

The continuing emphasis on whole-genome sequencing, and the concomitant development of 'post-genomics' approaches such as microarrays will impinge on studies on MHC evolution in several ways.

Firstly, by highlighting the importance of variation in MHC gene expression as well as in genotype for defining the fitness and adaptive potential of individuals. There is a growing understanding of how gene expression can play an important role in determining phenotypic variation (Oleksiak et al, 2002; Darvasi, 2003; Abzhanov et al, 2004), and allelic variation in promoter regions controlling HLA expression (Cowell et al, 1998) implies that this may also be true for MHC. However, just as characterising MHC genes in non-model species was perceived as a potential stumbling block to the study of MHC variation in non-model species, so might the identification and analysis of $\mathrm{MHC}$ regulatory regions in this case.

Secondly, technologies such as microarrays will identify genes with expression patterns that covary with MHC to particular selection pressures. These represent 
potential candidates for genes that show evolutionary patterns consistent with the effects of positive selection, and impact on individual fitness (Fitzpatrick et al, 2005). Paterson et al (1998) showed that specific MHC alleles explained variation in gastro-intestinal nematode parasite burden in free-living Soay Sheep. A subsequent study showed that individuals carrying specific microsatellite alleles at a locus closely linked to the interferon- $\gamma$ gene also had reduced levels of the same parasite and increased titre of circulating parasite-specific antibodies (Coltman et al, 2001). Several other potential candidate genes that play an important role in defining an individual's defense against immune insult have been identified (Behnke et al, 2003), and more can be readily identified in array-based analyses.

Clearly, while examination of MHC in non-model systems has increased our understanding of how genes can be influenced by selection, and themselves influence ecological processes, there are sufficient unanswered questions and new avenues of research to suggest that MHC will remain a major focus, and the number of studies examining MHC diversity will continue to increase at a rate similar to the past decade.

\section{Acknowledgements}

We thank the Natural Environment Research Council for financial support.

\section{References}

Abzhanov A, Protas M, Grant BR, Grant PR, Tabin CJ (2004). Bmp4 and morphological variation of beaks in Darwin's Finches. Science 305: 1462-1465.

Acaro K, Eklund A (1999). A review of MHC-based mating preferences and fostering experiments in two congenic strains of mice. Genetica 104: 241-244.

Aguilar A, Roemer G, Debenham S, Binns M, Garcelon D, Wayne RK (2004). High MHC diversity maintained by balancing selection in an otherwise genetically monomorphic mammal. Proc Natl Acad Sci USA 101: 3490-3494.

Alberts SC, Ober C (1993). Genetic variability of the MHC: a review of non-pathogen mediated selective mechanisms. YearB Phys Anthropol 36: 71-89.

Altuvia Y, Margalit H (2004). A structure-based approach for prediction of MHC-binding peptides. Methods 34: 454-459.

Apanius V, Penn D, Slev PR, Ruff LR, Potts WK (1997). The nature of selection on the major histocompatibility complex. Crit Rev Immunol 17: 179-224.

Arkush KD, Giese AR, Mendonca HL, McBride AM, Marty GD, Hedrick PW (2002). Resistance to three pathogens in the endangered winter-run chinook salmon (Oncorhynchus tshawytscha): effects of inbreeding and major histocompatibility complex genotypes. Can J Fish Aqu Sci 59: 966-975.

Beauchamp GK, Yamazaki K (2003). Chemical signalling in mice. Biochem Soc Trans 31: 147-151.

Begovich AB, Moonsamy PV, Mack SJ, Barcellos LF, Steiner LL, Grams S et al (2001). Genetic variability and linkage disequilibrium within the HLA-DP region: analysis of 15 different populations. Tissue Antigens 57: 424-439.

Behnke JM, Iraqi F, Mengel D, Baker RL, Gibson J, Wakelin D (2003). Chasing the genes that control resistance to gastrointestinal nematodes. J Helminthol 77: 99-109.

Bernatchez L, Landry C (2003). MHC studies in nonmodel vertebrates: what have we learned about natural selection in 15 years? J Evol Biol 16: 363-377.
Bierne N, Eyre-Walker A (2003). The problem of counting sites in the estimation of the synonymous and nonsynonymous substitution rates: implications for the correlation between the synonymous substitution rate and codon usage bias. Genetics 165: 1587-1597.

Borghans JAM, Beltman JB, De Boer RJ (2004). MHC polymorphism under host-pathogen coevolution. Immunogenetics 55: 732-739.

Boyce WM, Hedrick PW, MuggliCockett NE, Kalinowski S, Penedo MCT, Ramey RR (1997). Genetic variation of major histocompatibility complex and microsatellite loci: a comparison in bighorn sheep. Genetics 145: 421-433.

Briles WE, Stone HA, Cole RK (1977). Marek's Disease: effects of $B$ histocompatibility alloalleles in resistant and susceptible chicken lines. Science 195: 193-195.

Brown JL, Eklund A (1994). Kin recognition and the major histocompatibility complex: an integrative review. Am Naturalist 143: 435-461.

Buechner HK (1960). The bighorn sheep of the United States: its past, present and future. Wildlife Monogr 4: 1-174.

Buitkamp J, Filmether P, Stear MJ, Epplen JT (1996). Class I and class II major histocompatibility complex alleles are associated with faecal egg counts following natural, predominantly Ostertagia circumcincta infection. Parasitol Res 82 693-696.

Chesser R (1991a). Gene diversity and female philopatry. Genetics 127: 437-447.

Chesser R (1991b). Influence of gene flow and breeding tactics on gene diversity within populations. Genetics 129: 573-583.

Coltman DW, Wilson K, Pilkington JG, Stear MJ, Pemberton JM (2001). A microsatellite polymorphism in the gamma interferon gene is associated with resistance to gastrointestinal nematodes in a naturally-parasitized population of Soay sheep. Parasitology 122: 571-582.

Cowell L, Kepler T, Janitz M, Lauster R, Mitchison N (1998). The distribution of variation in regulatory gene segments, as present in MHC class II promotors. Genome Res 8: 124-134.

Darvasi A (2003). Gene expression meets genetics. Nature 422: 269-270.

De Boer RJ, Borghans JAM, van Boven M, Kesmir C, Weissing FJ (2004). Heterozygote advantage fails to explain the high degree of polymorphism of the MHC. Immunogenetics 55: 725-731.

Ditchkoff SS, Lochmiller RL, Masters RE, Hoofer SR, Van Den Bussche RA (2001). Major-histocompatibility-complex-associated variation in secondary sexual traits of white-tailed deer (Odocoileus virginianus): evidence for good-genes advertisement. Evolution 55: 616-625.

Dobson F (1998). Social structure and gene dynamics in mammals. I Mammal 79: 667-670.

Dobson F, Chesser R, Hoogland J, Sugg D, Foltz D (1997). Do black-tailed prairie dogs minimize inbreeding? Evolution 51: 970-978.

Dobson F, Chesser R, Hoogland J, Sugg D, Foltz D (1998). Breeding groups and gene dynamics in a socially structured population of prairie dogs. J Mammal 79: 671-680.

Doherty PC, Zinkernagel RM (1975). Enhanced immunological surveillance in mice heterozygous at the $\mathrm{H}-2$ gene complex. Nature 256: 50-52.

Edwards SV, Grahn M, Potts WK (1995). Dynamics of MHC evolution in birds and crocodilians - amplification of class-ii genes with degenerate primers. Mol Ecol 4: 719-729.

Edwards SV, Hedrick PW (1998). Evolution and ecology of MHC molecules: from genomics to sexual selection. TREE 13 305-311.

Edwards SV, Nusser J, Gasper J (2000). Characterization and evolution of Mhc genes from non-model organisms, with examples from birds. In: Baker AJ (ed) Molecular Methods in Ecology. Blackwell Scientific: Cambridge, pp 168-207.

Edwards SV, Potts WK (1996). Polymorphism of Mhc genes: implications for conservation genetics of vertebrates. In: 
Smith TB, Wayne RK (eds) Molecular Genetic Approaches to Conservation. Oxford University Press: Oxford, pp 214-237.

Egid K, Brown JL (1989). The major histocompatibility complex and female mating preferences in mice. Anim Behav 38: 548550.

Ekblom R, Saether SA, Grahn M, Fiske P, Kalas JA, Hoglund J (2004). Major histocompatibility complex variation and mate choice in a lekking bird, the great snipe (Gallinago media). Mol Ecol 13: 3821-3828.

Ewens WJ (1972). The Sampling Theory of Selectively Neutral Alleles. Theoret Popul Biol 3: 87-112.

Fitzpatrick MJ, Ben-Shahar Y, Smid HJ, Vet LEM, Robinson G, Sokolowski MB (2005). Candidate genes for behavioural ecology. Trends Ecol Evol 20: 96-104.

Flajnik MF, Kasahara M, Shum BP, Saltercid L, Taylor E, Dupasquier L (1993). A novel type of class-I gene organization in vertebrates - a large family of non-Mhc-linked class I genes is expressed at the RNA level in the amphibian Xenopus. EMBO J 12: 4385-4396.

Ford MJ (2002). Applications of selective neutrality tests to molecular ecology. Mol Ecol 11: 1245-1262.

Freeman-Gallant CR, Meguerdichian M, Wheelwright NT, Sollecito SV (2003). Social pairing and female mating fidelity predicted by restriction fragment length polymorphism similarity at the major histocompatibility complex in a songbird. Mol Ecol 12: 3077-3083.

Froeschke G, Sommer S (2005). MHC Class II DRB variability and parasite load in the striped mouse (Rhabdomys pumilio) in the southern Kalahari. Mol Biol Evol 22: 1254-1259.

Garrigan D, Hedrick PN (2001). Class I MHC polymorphism and evolution in endangered California Chinook and other Pacific salmon. Immunogenetics 53: 483-489.

Garrigan D, Hedrick PW (2003). Perspective: detecting adaptive molecular polymorphism: lessons from the MHC. Evolution 57: 1707-1722.

Gaudieri S, Dawkins RL, Habara K, Kulski JK, Gojobori T (2000). SNP profile within the human major histocompatibility complex reveals an extreme and interrupted level of nucleotide diversity. Genome Res 10: 1579-1586.

Geluk A, Elferink DG, Slierendregt BL, Vanmeijgaarden KE, Devries RRP, Ottenhoff THM et al (1993). Evolutionary conservation of major histocompatibility complex-Dr/Peptide/T-cell interactions in primates. J Exp Med 177: 979-987.

Gillespie JH (1978). A general model to account for enzyme variation in natural populations. V. The SAS-CFF model. Theoret Populat Genet 14: 1-45.

Girman D, Mills M, Geffen E, Wayne R (1997). A molecular genetic analysis of social structure, dispersal, and interpack relationships of the African wild dog (Lycaon pictus). Behav Ecol Sociobiol 40: 187-198.

Grafen A (1990). Do animals really recognize Kin. Anim Behav 39: $42-54$

Grimholt U, Larsen S, Nordmo R, Midtlyng P, Kjoeglum S, Storset A et al (2003). MHC polymorphism and disease resistance in Atlantic salmon (Salmo salar); facing pathogens with single expressed major histocompatibility class I and class II loci. Immunogenetics 55: 210-219.

Guillemot F, Kaufman JF, Skjoedt K, Auffray C (1989). The major histocompatibility complex in the chicken. Trends Genet 5: 300-304.

Gunther E, Walter L (2001). The major histocompatibility complex of the rat (Rattus norvegicus). Immunogenetics 53: 520-542.

Gutierrez-Espeleta GA, Hedrick PW, Kalinowski ST, Garrigan D, Boyce WM (2001). Is the decline of desert bighorn sheep from infectious disease the result of low MHC variation? Heredity 86: 439-450.

Hambuch TM, Lacey EA (2002). Enhanced selection for MHC diversity in social tuco-tucos. Evolution 56: 841-845.

Hansen JD, Strassburger P, Thorgarrd GH, Young WP, Du Pasquier L (1999). Expression, linkage and polymorphism of
MHC-related genes in rainbow trout, Oncorhynchus mykiss. Immunol 163: 774-786.

Harf R, Sommer S (2005). Association between major histocompatibility complex class II DRB alleles and parasite load in the hairy-footed gerbil, Gerbillurus paeba, in the southern Kalahari. Mol Ecol 14: 85-91.

Harris H (1966). Enzyme polymorphism in man. Proc Roy Soc London B 164: 298-310.

Hedrick P, Kim T (1998). Genetics of complex polymorphisms: parasites and maintenance of MHC variation. In: Singh R, Krimbas C (eds) Genetics, Evolution \& Society. Harvard University Press: Cambridge.

Hedrick PW (1992). Female choice and variation in the major histocompatibility complex. Genetics 132: 575-581.

Hedrick PW (1994). Evolutionary genetics of the major histocompatibility complex. Am Naturalist 143: 945-964.

Hedrick PW (1999). Perspective: highly variable loci and their interpretation in evolution and conservation. Evolution 53: 313-318.

Hedrick PW (2004a). Comment on 'parasite selection for immunogenetic optimality'. Science 303: 957.

Hedrick PW (2004b). Recent developments in conservation genetics. Forest Ecol Manag 197: 3-19.

Hedrick PW, Black FL (1997). HLA and mate selection: no evidence in South Amerindians. Am J Hum Genet 61: 505-511.

Hedrick PW, Ginevan M, Ewing E (1976). Genetic polymorphism in heterogeneous environments. Annu Rev Ecol Systemat 7: 1-32.

Hedrick PW, Kim TJ, Parker KM (2001). Parasite resistance and genetic variation in the endangered Gila topminnow. Anim Conserv 4: 103-109.

Hedrick PW, Parker KM, Gutierrez-Espeleta GA, Rattink A, Lievers K (2000). Major histocompatibility complex variation in the Arabian oryx. Evolution 54: 2145-2151.

Hess CW, Edwards SV (2002). The evolution of the major histocopatibility complex in birds. BioScience 52: 423-431.

Hey J (1999). The neutralist, the fly and the selectionist. TREE 14: 35-38.

Hill AVS (1998). The immunogenetics of human infectious diseases. Annu Rev Immunol 16: 593-617.

Hill AVS (1999). The immunogenetics of resistance to malaria. Proc Assoc Am Phys 111: 272-277.

Hill AVS, Allsopp EM, Kwaitkowski D, Anstey NM, Twumasi P, Rowe P et al. (1991). Common West African HLA antigens are associated with protection from severe malaria. Nature 352: 595-600.

Hill AVS, Elvin J, Willis AC, Aidoo M, Allsopp CEM, Gotch FM et al (1992). Molecular analysis of the association of Hla-B53 and resistance to severe malaria. Nature 360: 434-439.

Hill AVS, Yates SNR, Allsopp CEM, Gupta S, Gilbert SC, Lalvani A et al (1994). Human-leukocyte antigens and natural-selection by malaria. Philos Trans $R$ Soc London Ser B-Biol Sci 346: 379-385.

Hill RE, Hastie ND (1987). Accelerated evolution in the reactive center regions of serine protease inhibitors. Nature 326: 96-99.

Hoelzel AR, Stephens JC, O'Brien SJ (1999). Molecular genetic diversity and evolution at the MHC DQB locus in four species of pinnipeds. Mol Biol Evol 16: 611-618.

Huang SW, Yu HT (2003). Genetic variation of microsatellite loci in the major histocompatibility complex (MHC) region in the southeast Asian house mouse (Mus musculus castaneus). Genetica 119: 201-218.

Hughes A, Hughes M (1995). Natural selection on the peptidebinding regions of the major histocompatibility complex molecules. Immunogenetics 42: 233-243.

Hughes AL (1999). Adaptive Evolution of Genes and Genomes. Oxford University Press: New York.

Hughes AL, Nei M (1988). Pattern of nucleotide substitution at major histocompatibility complex class I loci reveals overdominant selection. Nature 335: 167-170. 
Hughes AL, Nei M (1989). Nucleotide substitution at major histocompatibility complex class II loci: evidence for overdominant selection. Proc Natl Acad Sci USA 86: 958-962.

Hughes AL, Yeager M (1998). Natural selection at major histocompatibility complex loci of vertebrates. Annu Rev Genet 32: 415-435.

Hurst JL, Payne CE, Nevison CM, Marie AD, Humphries RE, Robertson DHL et al (2001). Individual recognition in mice mediated by major urinary proteins. Nature 414: 631-634.

Hurt P, Walter L, Sudbrak R, Klages S, Muller I, Shiina T et al (2004). The genomic sequence and comparative analysis of the rat major histocompatibility complex. Genome Res 14: 631-639.

Jeffrey KJ, Bangham RM (2000). Do infectious diseases drive MHC diversity? Microbes Infect 2: 1335-1341.

Johnsen A, Andersen V, Sunding C, Lifjeld JT (2000). Female bluethroats enhance offspring immunocompetence through extra-pair copulations. Nature 406: 296-299.

Jordan WC, Bruford MW (1998). New perspectives on mate choice and the MHC. Heredity 81: 239-245.

Kaufman J, Milne S, Gobel TWF, Walker BA, Jacob JP, Zoorob R et al (1999). The chicken B locus is a minimal essential major histocompatibility complex. Nature 401: 923-925.

Kaufman J, Salomonsen J (1997). The 'minimal essential MHC' revisited: both peptide-binding and cell surface expression level of MHC molecules are polymorphisms selected by pathogens in chickens. Hereditas 127: 67-73.

Kaufman J, Volk H, Wallny HJ (1995). A minimal essential mhc and an unrecognized mhc - 2 extremes in selection for polymorphism. Immunol Rev 143: 63-88.

Kelley J, Walter L, Trowsdale J (2005). Comparative genomics of major histocompatibility complexes. Immunogenetics 56: 683-695.

Kimura M (1983). The Neutral Theory of Molecular Evolution. Cambridge University Press: New York.

Klein J (1980). Generation of diversity at MHC loci: implications for T-cell receptor repertoires. In: Fougereau M, Dausset J (eds) Immunology 80. Academic Press: London, pp 239-253.

Klein J (1986). Natural History of the Major Histocompatibility Complex, 1st edn. John Wiley \& Sons: New York, Chichester, Brisbane, Toronto, Singapore.

Knapp LA (2005). Facts, faeces and setting standards for the study of MHC genes using non-invasive samples. Mol Ecol 14: 1597-1600.

Kreitman M (2000). Methods to detect selection in populations with applications to the human. Annu Rev Genom Hum Genet 1: 539-559.

Kreitman M, Akashi H (1995). Molecular Evidence for naturalselection. Annu Rev Ecol Syst 26: 403-422.

Kuroda N, Figueroa F, O'hUigin C, Klein J (2002). Evidence that the separation of Mhe class II from class I loci in the zebrafish, Danio rerio, occurred by translocation. Immunogenetics 54: 418-430.

Landry C, Bernatchez L (2001). Comparative analysis of population structure across environments and geographical scales at major histocompatibility complex and microsatellite loci in Atlantic salmon (Salmo salar). Mol Ecol 10: 2525-2539.

Landry C, Garant D, Duchesne P, Bernatchez L (2001). Good genes as heterozygosity': the major histocompatibility complex and mate choice in Atlantic salmon (Salmo salar). Proc $R$ Soc London Ser B-Biol Sci 268: 1279-1285.

Langefors A, Lohm J, Grahn M, Andersen O, von Schantz T (2001). Association between major histocompatibility complex class IIB alleles and resistance to Aeromonas salmonicida in Atlantic salmon. Proc R Soc London Ser B-Biol Sci 268: 479-485.

Lenington $S$ (1994). Of mice, men and the MHC. TREE 9: 455-456.

Lewontin RC, Hubby JL (1966). A molecular approach to the study of genic heterozygosity in natural populations. II. Amount of variation and the degree of heterozygosity in natural populations of Drosophila pseudoobscura. Genetics 54: 595-609.
Lohm J, Grahn M, Langefors A, Andersen O, Storset A, von Schantz T (2002). Experimental evidence for major histocompatibility complex - allele-specific resistance to a bacterial infection. Proc $R$ Soc London Ser B-Biol Sci 269: 2029-2033.

Lukas D, Vigilant L (2005). Reply: facts, faeces and setting standards for the study of MHC genes using non-invasive samples. Mol Ecol 14: 1601-1602.

Mack SJ, Bugawan TL, Moonsamy PV, Erlich JA, Trachtenberg EA, Paik YK et al (2000). Evolution of Pacific/Asian populations inferred from HLA class II allele frequency distributions. Tissue Antigens 55: 383-400.

Manning C, Potts W, Wakeland E, Dewsbury D (1992). Whats wrong with MHC mate choice experiments? In: Doty R, Muller-Schwarze D (eds) Chemical Signals in Vertebrates VI. Plenum Press: New Yourk, pp 229-235.

Martinsohn JT, Sousa AB, Guethlein LA, Howard JC (1999). The gene conversion hypothesis of MHC evolution: a review. Immunogenetics 50: 168-200.

Massingham T, Goldman N (2005). Detecting amino acid sites under positive selection and purifying selection. Genetics 169: 1753-1762.

Mays HL, Hill GE (2004). Choosing mates: good genes versus genes that are a good fit. Trends Ecol Evol 19: 554-559.

McClelland EE, Penn DJ, Potts WK (2003). Major histocompatibility complex heterozygote superiority during coinfection. Infect Immun 71: 2079-2086.

Meyer-Lucht Y, Sommer S (2005). MHC diversity and the association to nematode parasitism in the yellow-necked mouse (Apodemus flavicollis). Mol Ecol 14: 2233-2244.

MHC Sequencing Consortium (1999). Complete sequence and gene map of a human major histocompaibility complex. Nature 401: 921-923.

Miller HC, Lambert DM (2003). An evaluation of methods of blood preservation for RT-PCR from endangered species. Conserv Genet 4: 651-654.

Miller KM, Kaukinen KH, Beacham TD, Withler RE (2001). Geographic heterogeneity in natural selection on an MHC locus in sockeye salmon. Genetica 111: 237-257.

Miller KM, Winton JR, Schulze AD, Purcell MK, Ming TJ (2004). Major histocompatibility complex loci are associated with susceptibility of Atlantic salmon to infectious hematopoietic necrosis virus. Environ Biol Fishes 69: 307-316.

Miller KM, Withler RE (1997). Mhc diversity in Pacific salmon: population structure and trans-species allelism. Hereditas 127: 83-95.

Muirhead CA (2001). Consequences of population structure on genes under balancing selection. Evolution 55: 1532-1541.

Musolf K, Meyer-Lucht Y, Sommer S (2004). Evolution of MHCDRB class II polymorphism in the genus Apodemus and a comparison of DRB sequences within the family Muridae (Mammalia: Rodentia). Immunogenetics 56: 420-426.

Nei M (1987). Mol Evol Genet. Columbia University Press: New York.

Nevo E, Beiles A (1992). Selection for class-Ii Mhc heterozygosity by parasites in subterranean mole rats. Experientia 48: $512-515$.

Nielsen R (1997). The ratio of replacement to silent divergence and tests of neutrality. J Evol Biol 10: 217-231.

Nielsen R, Yang ZH (1998). Likelihood models for detecting positively selected amino acid sites and applications to the HIV-1 envelope gene. Genetics 148: 929-936.

Nowak MA, Tarczyhornoch K, Austyn JM (1992). The Optimal Number of Major Histocompatibility Complex- Molecules in an Individual. Proc Natl Acad Sci USA 89: 10896-10899.

Ober C, Weitkamp L, Cox N, Dytch H, Kostyu D, Elias S (1997). HLA and mate choice in humans. Am I Hum Genet 61: 497-504.

Oleksiak MF, Churchill GA, Crawford DL (2002). Variation in gene expression within and among natural populations. Nat Genet 32: 261-266. 
Olsen KH, Grahn M, Lohm J (2002). Influence of mhc on sibling discrimination in Arctic char, Salvelinus alpinus (L.). J Chem Ecol 28: 783-795.

Olsen KH, Grahn M, Lohm J, Langefors A (1998). MHC and kin discrimination in juvenile Arctic charr, Salvelinus alpinus (L.) Anim Behav 56: 319-327.

Olsson M, Madsen T, Nordby J, Wapstra E, Ujvari B, Wittsell H (2003). Major histocompatibility complex and mate choice in sand lizards. Proc R Soc London Ser B-Biol Sci 270: S254-S256.

Olsson M, Madsen T, Ujvari B, Wapstra E (2004). Fecundity and MHC affects ejaculation tactics and paternity bias in sand lizards. Evolution 58: 906-909.

Paterson S (1998). Evidence for balancing selection at the major histocompatibility complex in a free-living ruminant. J Hered 89: 289-294.

Paterson S, Pemberton JM (1997). No evidence for major histocompatibility complex-dependent mating patterns in a free- living ruminant population. Proc $R$ Soc London 264 1813-1819.

Paterson S, Wilson K, Pemberton JM (1998). Major histocompatibility complex variation associated with juvenile survival and parasite resistance in a large unmanaged ungulate population (Ovis aries L.). Proc Natl Acad Sci USA 95: 37143719.

Penn D, Potts WK (1998). Chemical signals and parasitemediated sexual selection. TREE 13: 391-396.

Penn DJ, Damjanovich K, Potts WK (2002). MHC heterozygosity confers a selective advantage against multiple-strain infections. Proc Natl Acad Sci USA 99: 11260-11264.

Penn J, Potts WK (1999). The evolution of mating preferences and major histocompatibility complex genes. Am Naturalist 153: $145-164$.

Pfau RS, Van Den Bussche RA, McBee K (2001). Population genetics of the hispid cotton rat (Sigmodon hispidus): patterns of genetic diversity at the major histocompatibility complex. Mol Ecol 10: 1939-1945.

Piertney SB (2003). Major histocompatibility complex B-LB gene variation in red grouse Lagopus lagopus scoticus. Wildlife Biol 9: 251-259.

Piertney SB, MacColl ADC, Lambin X, Moss R, Dallas JF (1999). Spatial distribution of genetic relatedness in a moorland population of red grouse (Lagopus lagopus scoticus). Biol J Linnean Soc 68: 317-331.

Potts WK (1996). PCR-based cloning across large taxonomic distances and polymorphism detection: $\mathrm{MHC}$ as a case study. In: Ferraris JD, Palumbi SR (eds) Molecular Zoology: Advances, Strategies and Protocols. Wiley: New York, pp 181-194.

Potts WK, Manning CJ, Wakeland EK (1991). Mating patterns in seminatural populations of mice influenced by Mhc genotype. Nature 352: 619-621.

Potts WK, Slev PR (1995). Pathogen-based models favoring MHC genetic diversity. Immunol Rev 143: 181-197.

Potts WK, Wakeland EK (1990). Evolution of diversity at the major histocompatibility complex. TREE 5: 181-187.

Potts WK, Wakeland EK (1993). Evolution of MHC genetic diversity - a tale of incest, pestilence and sexual preference. Trends Genet 9: 408-412.

Radtkey RR, Becker B, Miller RD, Riblet R, Case TJ (1996) Variation and evolution of class I Mhc in sexual and parthenogenetic geckos. Proc $R$ Soc London Ser B-Biol Sci 263: 1023-1032.

Reusch TBH, Haberli MA, Aeschlimann PB, Milinski M (2001). Female sticklebacks count alleles in a strategy of sexual selection explaining MHC polymorphism. Nature 414: 300-302.

Richardson DS, Westerdahl H (2003). MHC diversity in two Acrocephalus species: the outbred Great reed warbler and the inbred Seychelles warbler. Mol Ecol 12: 3523-3529.

Rulicke T, Chapuisat M, Homberger FR, Macas E, Wedekind C (1998). MHC-genotype of progeny influenced by parental infection. Proc R Soc London Ser B-Biol Sci 265: 711-716.
Santos PC, Schinemann JA, Gabaro J, de Graca Bichalho M (2004). New evidence on MHC-based disassortative odour preferences in humans: a study with 58 Brazilian students. Hum Immunol 65: 108.

Sauermann U, Nurnberg P, Bercovitch FB, Berard JD, Trefilov A, Widdig A et al (2001). Increased reproductive success of MHC class II heterozygous males among free-ranging rhesus macaques. Hum Genet 108: 249-254.

Schad J, Ganzhorn JU, Sommer S (2005). Parasite burden and constitution of major histocompatibility complex in the Malagasy mouse lemur, Microcebus murinus. Evolution 59: 439-450.

Schierup MH (1998). The number of self-incompatibility alleles in a finite, subdivided population. Genetics 149: 1153-1162.

Schierup MH, Vekemans X, Charlesworth D (2000). The effect of subdivision on variation at multi-allelic loci under balancing selection. Genet Res 76: 51-62.

Schwaiger FW, Gostomski D, Stear MJ, Duncan JL, McKellar QA, Epplen JT et al (1995). An ovine major histocompatibility complex Drb1 allele is associated with low fecal egg counts following natural, predominantly Ostertagia circumcincta infection. Int J Parasitol 25: 815-822.

Seddon JM, Ellegren H (2004). A temporal analysis shows major histocompatibility complex loci in the Scandinavian wolf population are consistent with neutral evolution. Proc $R$ Soc London Ser B-Biol Sci 271: 2283-2291.

Shiina T, Imanishi T, Habara T, Aono R, Yamaguchi K (2002). Comparative genome sequencing analyses of $\mathrm{MHC}$ regions and establishment of MHC integrated database (M-INTEGRA). Tissue Antigens 59: 7.

Singh PB, Brown RE, Roser B (1987). Mhc antigens in urine as olfactory recognition cues. Nature 327: 161-164.

Slade RW, McCallum HI (1992). Overdominant $v$ s frequencydependent selection at MHC loci. Genetics 132: 861-862.

Sommer S (2003). Effects of habitat fragmentation and changes of dispersal behaviour after a recent population decline on the genetic variability of noncoding and coding DNA of a monogamous Malagasy rodent. Mol Ecol 12: 2845-2851.

Sugg D, Chesser R (1994). Effective population sizes with multiple paternity. Genetics 137: 1147-1155.

Sugg D, Chesser R, Dobson F, Hoogland J (1996). Population genetics meets behavioral ecology. Trends Ecol Evol 11: 338-342.

Suzuki Y (2004). New methods for detecting positive selection at single amino acid sites. J Mol Evol 59: 11-19.

Takahata N, Nei M (1990). Allelic genealogy under overdominant and frequency-dependent selection and polymorphism of major histocompatibility complex loci. Genetics 124: 967-978.

Tregenza T, Wedell N (2000). Genetic compatibility, mate choice and patterns of parentage: invited review. Mol Ecol 9: 1013-1027.

Van Den Bussche RA, Ross TG, Hoofer SR (2002). genetic variation at a major histocompatibility locus within and among populations of white-tailed deer (Odocoileus virginianus). J Mammal 83: 31-39.

von Schantz T, Goransson G, Andersson G, Froberg I, Grahn M, Helgee $M$ et al (1989). Female choice selects for a viabilitybased male trait in pheasant. Nature 337: 166-169.

von Schantz T, Wittzell H, Goransson G, Grahn M (1997). Mate choice, male condition-dependent ornamentation and MHC in the pheasant. Hereditas 127: 133-140.

von Schantz T, Wittzell H, Goransson G, Grahn M, Persson K (1996). MHC genotype and male ornanmentation: genetic evidence for the Hamilton-Zuk model. Proc R Soc London Ser B 263: 265-271.

Watterson GA (1978). The homozygosity test of neutrality. Genetics 88: 405-417.

Wedekind C, Chapuisat M, Macas E, Rulicke T (1996). Nonrandom fertilization in mice correlates with the MHC and something else. Heredity 77: 400-409. 
Wedekind C, Furi S (1997). Body odour preferences in men and women: do they aim for specific MHC combinations or simply heterozygosity? Proc R Soc London Ser B-Biol Sci 264: 1471-1479.

Wedekind C, Seebeck T, Bettens F, Paepke AJ (1995). MHCdependent mate preferences in humans. Proc Roy Soc London Ser B-Biol Sci 260: 245-249.

Wedekind C, Walker M, Portmann J, Cenni B, Muller R, Binz T (2004). MHC-linked susceptibility to a bacterial infection, but no MHC-linked cryptic female choice in whitefish. J Evol Biol 17: 11-18.

Wegner KM, Kalbe M, Kurtz J, Reusch TBH, Milinski M (2003a). Parasite selection for immunogenetic optimality. Science 301: 1343.

Wegner KM, Kalbe M, Kurtz J, Reusch TBH, Milinski M (2004). Response to comment on 'Parasite selection for immunogenetic optimality'. Science 303: U2.

Wegner KM, Reusch TBH, Kalbe M (2003b). Multiple parasites are driving major histocompatibility complex polymorphism in the wild. I Evol Biol 16: 224-232.

Westerdahl H (2004). No evidence of an MHC-based female mating preference in great reed warblers. Mol Ecol 13: 2465-2470

Westerdahl H, Hansson B, Bensch S, Hasselquist D (2004). Between-year variation of MHC allele frequencies in great reed warblers: selection or drift? J Evol Biol 17: 485-492.
Widdig A, Bercovitch FB, Streich WJ, Sauermann U, Nurnberg P, Krawczak M (2004). A longitudinal analysis of reproductive skew in male rhesus macaques. Proc Roy Soc London Ser B-Biol Sci 271: 819-826.

Yamazaki K, Beachamp G, Kupniewski D, Bard J, Thomas L, Boyse EA (1988). Familial imprinting determines H-2 selective mating preferences. Science 240: 1331-1332.

Yamazaki K, Boyse EA, Mike V, Thaler HT, Mathieson BJ Abbott J et al (1976). Control of mating preferences in mice by genes in the major histocompatibility complex. J Exp Med 144: 1324-1335.

Yamazaki K, Yamagughi M, Baranoski L, Bard J, Boyse EA, Thomas L (1979). Recognition among mice: evidence from the use of a Y-maze differentially scented by congenic mice of different major histocompatibility types. J Exp Med 150: 755-760.

Yang Z, Nielsen R, Goldman N, Pedersen AMK (2000). Codonsubstitution models for heterogeneous selection pressures at amino acid sites. Genetics 155: 431-449.

Yang ZH, Nielsen R (2000). Estimating synonymous and nonsynonymous substitution rates under realistic evolutionary models. Mol Biol Evol 17: 32-43.

Younger RM, Amadou C, Bethel G, Ehlers A, Fischer Lindahl K (2000). Characterization of clustered MHC-linked olfactory receptor genes in human and mouse. Genome Res 11: 51930. 